\title{
MEMÓRIAS COLETIVAS, TRAUMAS INDIVIDUAIS: AS MEMÓRIAS DOS DESASTRES SOCIOAMBIENTAIS NO SUL DE SANTA CATARINA (1974-2004)
}

\author{
Collective Memories, Individual Traumas: \\ memories of social and environmental disasters in the \\ south of Santa Catarina (1974-2004)
}

Alfredo Ricardo Silva Lopes ${ }^{1}$

\begin{abstract}
RESUMO
$\mathrm{O}$ artigo tem por objetivo analisar as memórias coletivas dos entrevistados sobre os mais significativos desastres socioambientais ocorridos no sul de Santa Catarina de 1974 a 2004. Nesse caminho, são utilizadas entrevistas de História Oral dos moradores das áreas de risco que vivenciaram estas situações extremas. A narrativa dos entrevistados evidencia a condição de sobreviventes e a constante negociação entre memória e esquecimento na produção da compreensão dos desastres, tidos como de origem natural.
\end{abstract}

Palavras-chave: Desastres Socioambientais; Sul de Santa Catarina Memória; História Oral; Esquecimento.

\begin{abstract}
The objective of this article is to analyze the collective memories of the most significant socio-environmental disasters that occurred in the south of Santa Catarina from 1974 to 2004. In this way, Oral History interviews are used by the residents of the risk areas that experienced these extreme situations. The narrative of the interviewees shows the condition of survivor and constant negotiation between memory and forgetfulness during the production of understanding of the disasters understood as natural.
\end{abstract}

Keywords: Socio-environmental Disasters; South of Santa Catarina State; Memory; Oral History; Forgetfulness. 


\section{Introdução}

As memórias dos desastres tidos como naturais, diferentemente das memórias de guerra, têm marcadamente vida curta (MAUCH, 2003, p. 3), assim que o desastre se torna "matéria velha", a imprensa perde o interesse em publicar mais notícias. Com as águas voltando ao nível pré-enchente, o medo imposto pelo risco é deixado de lado em prol do esforço de reconstrução. Contudo, apesar do silêncio na maioria dos livros de história, as memórias dos desastres continuam vivas, deixadas em um estado de latência, acionada nos momentos de perigo.

A História Ambiental recentemente vem focando suas preocupações sobre os desastres entendidos como socioambientais, ou seja, produzidos ou potencializados não só pelas forças do mundo natural, mas, também, pelas estratégias políticas, econômicas e culturais utilizadas pelos seres humanos para interagir com o meio ambiente. Ted Steinberg, em Acts of God: The Unnatural History of Natural Disaster in America (2000), enfatiza a crescente desmistificação da ocorrência dos desastres ao longo do século XX. Ao abordar o Rio de Janeiro da década de 1960, a historiadora Lise Sedrez (2013) destaca a ação do Estado e as expectativas da população sobre elas. Uma das preocupações de Sedrez está em evidenciar como a sensação de segurança criada pela vida em sociedade é destruída pela ocorrência do desastre. Já o historiador ambiental inglês Greg Bankoff, ao tratar das ameaças constantes de desastres a que os filipinos estão sujeitos, destaca ferramentas culturais usadas para interagir com a situação de risco, em que fica evidente o alargamento da ideia de normalidade. Neste contexto, o desastre não é compreendido como anormal, diferente do que as ciências sociais ocidentais têm preconizado (BANKOFF, 2009).

$\mathrm{O}$ primeiro artigo publicado no Brasil que analisa os desastres e memórias é de Andréa Casa Nova Maia e Lise Sedrez, Narrativas de um Dilúvio Carioca: memória e natureza na Grande Enchente de 1966 (2011). No estudo as autoras utilizam a história ambiental e a história oral para responder inicialmente às inquietações da experiência de uma memória ambiental que passa pela vivência cotidiana no espaço construído, onde em determinados momentos a cidade fica alagada, paralisada, submersa. Um segundo ponto diz respeito à história social da cidade do Rio de Janeiro, “[...] ou seja, como a população viveu a experiência das enchentes ao longo do século XX" (MAIA; SEDREZ, 2011, p. 224). A inter-relação entre elementos sociais, culturais e ambientais marca a conclusão do artigo, que enfatiza o 
[...] resultado danoso de uma mistura perigosa: ocupação de áreas pantanosas e/ou mangues com a diminuição da capacidade de absorção do solo, em uma área onde a chuva é parte do ecossistema num processo de urbanização desgovernado (MAIA; SEDREZ, 2011, p. 254).

Neste caso, o desastre aparece como o agente catalisador de uma reação química que nunca para de ocorrer, as relações sociais. A intempérie, segundo as autoras, também desconstrói uma sensação de falsa segurança que é fornecida pela vida em sociedade, frente às determinações impostas pelo ambiente. Além disso, não se pode perceber os desastres como todos acontecendo da mesma maneira, mesmo que diversas enchentes incidam sobre o mesmo território, cada acontecimento possuirá sua especificidade (MAIA; SEDREZ, 2011).

O presente artigo discute o lugar das memórias na vida das pessoas que sobreviveram aos desastres no sul do Estado de Santa Catarina. Ao debater o lugar das memórias na vida das pessoas, ambiciona-se compreender a função tanto da memória dessas "situações limite" quanto do seu esquecimento na vida dos entrevistados. Cabe destacar que, de maneira consciente, este trabalho se vale exclusivamente das fontes orais para compor sua análise. A utilização exclusiva deste tipo de fonte não ocorre pela crença de que os testemunhos orais são a "verdade que emana do povo" (ALBERTI, 2006), muito comum nos estudos da década de 1980 no Brasil, mas, sim, pelo contato com os mais variados tipos de experiências e memórias que não são encontrados nos registros escritos.

Portanto, com base em entrevistas realizadas pela metodologia da História Oral, são levantadas as memórias dos indivíduos que sobreviveram aos desastres ambientais no extremo sul de Santa Catarina. O recorte cronológico escolhido vai de 1974 a 2004, e tem como base os desastres mais marcantes tanto na memória dos entrevistados, quanto nos registros produzidos pelos periódicos e Defesa Civil. Receberam destaque: a enchente e os deslizamentos de $1974^{2}$ espalhados nessa região; a enchente e os

2 A enchente de 1974 poderia ser chamada de "as enchentes de 1974", pois, apesar de um mesmo evento se estender por todo o sul catarinense e norte do Rio Grande do Sul, oficialmente foram computadas 199 mortes e toda região ficou paralisada por meses. 
deslizamentos de $1995^{3}$ no extremo sul; e, finalmente, o Furacão Catarina ${ }^{4}$ que chegou à costa catarinense em 2004 ${ }^{5}$. Diversos outros desastres menos impactantes foram arrolados pelos entrevistados como importantes, mas estes três podem ser vistos como desastres arquétipos, calamidades que devido às suas proporções ou a características especiais solapam a memória de outros eventos (STEINBERG, 2006, p. 25).

Inicialmente cabem algumas considerações sobre as características das entrevistas. Foram realizadas 29 entrevistas entre 2011 e 2014, nas áreas rural e urbana das cidades da região no Sul de Santa Catarina, totalizando 193 páginas de material transcrito. As entrevistas valeram-se de eixos temáticos para direcionar a narrativa, pois na maioria das vezes os desastres não são vistos como elementos capazes de influenciar as experiências de vida, salvo exceções onde houve mortes na família ou destruição vultuosa de bens.

Dada a complexidade da temática e a natureza traumática dos desastres, o contato inicial com os entrevistados era realizado da maneira mais clara possível. Destacava-se que se tratava de uma pesquisa sobre as memórias dos desastres que incidiram sobre a região e, nesse caso, toda memória seria importante. A recusa pela entrevista aconteceu nas cidades de Araranguá e Tubarão. Contudo, esses episódios não tratavam dos indivíduos que evitavam memórias traumáticas, mas, sim, de pessoas que apesar de terem vivido enchentes, não se viam como vulneráveis a elas.

Foram priorizados entrevistados que teriam vivido os acontecimentos de 1974 a 2004, para que os relatos viessem impregnados pela gama mais diversa possível de memórias dos desastres. A enchente de 1974 se mostrou um marco na memória dos desastres, seja pela proporção, seja pelo número de mortos. Depois dela, a enchente e deslizamentos de dezembro de 1995 no extremo sul do Estado se fizeram ecoar na memória coletiva. No final das entrevistas, surgindo na maioria das vezes espontaneamente, aparecia 0 Furacão Catarina de 2004, com a marca indelével da excepcionalidade que traduz a ocorrência dos desastres.

\footnotetext{
3 Em virtude da estiagem prolongada, com uma forte chuva se produziu um deslocamento de massa da Serra Geral que atingiu vários municípios no extremo sul de SC. Foram encontrados 15 corpos e 7 pessoas foram dadas como desaparecidas.

4 Primeiro Furacão do Atlântico Sul. Avançou sobre o norte do RS e sul de SC causando prejuízos da ordem de R\$ 339 milhões. Um homem em terra morreu durante a passagem do Furacão e sete morreram no mar. 5 O Sul do Estado de Santa Catarina ocupa uma área de $9.049 \mathrm{~km}^{2}(9,8 \%$ da área total do Estado). Compreende 39 municípios com uma população estimada em 800 mil habitantes. As principais cidades são Criciúma, Tubarão e Araranguá.
} 


\section{Memória Coletiva e História Oral}

Aobra do sociólogo francês Maurice Halbwachs, AMemória Coletiva publicada originalmente em 1950, cinco anos após a sua morte, é basilar para os atuais estudos sobre a memória nas ciências humanas. O pensamento de Halbwachs se apresentou como uma contraposição às tendências filosóficas e sociológicas tributárias do idealismo e mecanicismo que dominavam a cena intelectual dos primeiros anos do século XX. Halbwachs buscava principalmente se opor ao materialismo de Henri Bergson.

Para Halbwachs o indivíduo que lembra é sempre um indivíduo inserido e habitado por grupos de referência. A memória, então, é sempre constituída em um grupo, mas nunca deixa também de ser trabalho do sujeito.

Fazemos apelo aos testemunhos para fortalecer ou debilitar, mas também para completar, o que sabemos de um evento do qual já estamos informados de alguma forma, embora muitas circunstâncias nos pareçam obscuras. Ora, a primeira testemunha, à qual podemos sempre apelar, é a nós próprios (HALBWACHS, 1990, p. 25).

Neste caminho, a memória é constituída como um trabalho de reconhecimento e reconstrução definido pela articulação das lembranças, onde o trabalho da memória é, também, tornar presente um conjunto de testemunhos para dar sentido ao tempo atual. A memória coletiva passa a ser o trabalho que um determinado grupo realiza a fim de articular e localizar as lembranças em um "acervo" comum (SCHIMIDT; MAHFOUD, 1993, p. 291).

Jacques Le Goff oferece uma definição para o conceito de memória que se estabeleceu após a década de 1980, principalmente com a retomada das pesquisas sobre os relatos de guerra. Como aponta o historiador francês em História e Memória,

(...) a ciência histórica define-se em relação a uma realidade que não é nem construída nem observada como na matemática, nas ciências da natureza e nas ciências da vida, mas sobre a qual se 
'indaga', 'se testemunha'. (...) Assim, a história começou como um relato, a narração daquele que pode dizer 'Eu vi, eu senti' (LE GOFF, 2003, p. 09).

Desta forma, a história-testemunho jamais deixou de estar presente no desenvolvimento da ciência histórica, no momento em que os autores produziam as suas obras. Durante a década de 1970, na França, assistiu-se ao surgimento desse tipo de preocupação. Isto, segundo Le Goff, "devido à vontade de colocar a explicação no lugar da narração” (LE GOFF, 2003, p. 09).

Entretanto, com o redimensionamento da noção de fato histórico, levando-o para além do status de objeto dado e acabado, a históriatestemunho tem seu renascimento e a noção documento-monumento passa a ser estendida a outros tipos de fontes. Desta forma, será utilizado o conceito de memória defendido pelo historiador,

[...]a memória, como propriedade de conservar certas informações, remete-nos em primeiro lugar a um conjunto de funções psíquicas, graças as quais o homem pode atualizar impressões ou informações passadas, ou que ele representa como passadas (LE GOFF, 2003, p. 419).

Le Goff ainda veicula as sobreposições não hierárquicas entre a memória individual e a memória coletiva como essenciais à formação do que se convencionou chamar identidade, cuja busca é uma afinidade dos indivíduos na sociedade de hoje. Tocantes a este trabalho, os relatos memorialísticos focalizam as "histórias dentro da história"; esta afirmação baliza-se nas considerações de Verena Alberti em Fontes Históricas (2006). Para a autora, um acontecimento vivido tem que ser narrado para que seja transmitido. Nesse processo, o entrevistado seleciona e organiza o que foi vivido através da linguagem para conferir sentido à experiência vivida. A busca por sentido existe tanto nas narrativas literárias, quanto nas não literárias, como a narrativa oral, por exemplo (ALBERTI, 2006, p. 171).

Dentro deste contexto de experiência, percepção e memória, a História Oral se apresenta como uma metodologia de pesquisa e de constituição de fontes para o estudo da História Contemporânea, onde são 
ampliadas as possibilidades de interpretação do passado (ALBERTI, 2006, p. 155). A historiadora Verena Alberti reitera que com a intensa valorização das fontes orais no Brasil, nos anos 1980, surgiu a crença de que as fontes orais trariam uma espécie de história-relato, onde a simples existência do relato já efetivá-lo-ia como história. Alberti afirma que o equívoco se concretizou quando a fonte oral foi consolidada pelos historiadores como "verdade emanada do povo", pois esta, como toda e qualquer fonte, deve ser inquirida (ALBERTI, 2006, p. 155).

O esquecimento como elemento necessário à vida também é analisado neste trabalho tendo em vista as memórias dos desastres. O filósofo Friedrich Nietzsche, ao discutir com os historiadores hegelianos do séc. XIX, defendia a necessidade do esquecimento, em contrapartida ao historicismo que aspirava à totalidade e unidade. Essa totalidade, enquanto conceito chave, estava pautada na aspiração de dar conta da história da humanidade, "é a partir dele [o esquecimento] que se pode demarcar a infância, a maturidade e a velhice da humanidade" (SOBRINHO, 2005, p. 36).

A estes chamados espíritos históricos; o espetáculo do passado os lança para o futuro, inflama sua coragem de viver e de lutar cada vez mais, ilumina neles a esperança de que a justiça está por vir, que a felicidade os espera do outro lado da montanha que eles pretendem escalar. Esses espíritos históricos acreditam que o sentido da existência se revela progressivamente no curso de um processo; eles só olham para trás para compreender o presente à luz do caminho já percorrido e para aprender a desejar mais ardentemente o futuro; eles não sabem o quanto apesar de todo o seu conhecimento histórico, pensam e agem de maneira a-histórica, não sabem o quanto sua atividade de historiador é ela própria comandada pela vida, e não pela pura busca do conhecimento (NIETZSCHE, 2005, p. 79).

Para o filósofo alemão, o esquecimento enquanto necessidade surgia em virtude da monumentalização do passado produzida pelos historiadores positivistas do século XIX. A crítica buscava contrapor a valorização de determinadas tradições, que degeneravam a história "a partir do momento em que não é mais animada e inspirada pelo sopro vivificante do presente" (NIETZSCHE, 2005, p. 95). As reflexões propostas por Nietzsche no final 
do século XIX podem parecer pontos já aceitos e sedimentados no seio da historiografia, entretanto, por mais que matrizes teleológicas sejam atualmente refutadas, a ideia de progresso ainda é central como elemento constitutivo dos processos sociais na sociedade ocidental.

Um século depois, Paul Ricoeur (2007) segue o rastro de Nietzsche e outros pensadores e oferece novas reflexões, não para o processo de institucionalização da história, mas para a função do esquecimento numa sociedade que cristalizou algumas memórias e deu espaço para estas lembranças no seio da história.

Neste ponto, as considerações de Antonio Torres Montenegro (2010), inicialmente balizadas pelo estudo de Walter Benjamin "O narrador: considerações sobre a obra de Nikolai Leskov", levantam a discussão sobre a arte de intercambiar experiências. Em História, metodologia, memória, Montenegro percorre sua trajetória de pesquisador discutindo e problematizando metodologicamente as diferentes situações que encontrou nessa caminhada intelectual.

Montenegro afirma que Benjamin temia a modernidade, pois foi com a invenção da imprensa que o romance pôde se difundir. A reprodutibilidade técnica inscrita no romance seria o "sinal fundamental dessa perda do caráter narrador, que se revelaria tanto no romance quanto na própria imprensa", pois estes nem

[...]'procedem da tradição oral nem a alimentam'. Nesse sentido, ainda, a própria imprensa, voltada predominantemente para a transmissão de informações, seria incapaz de alargar essa forma de comunicação de saberes, uma das dimensões fundadoras do narrador (MONTENEGRO, 2010, p. 49-50).

Isto ocorre pelo fato de que, segundo Benjamin (1985, p. 201), “(...) a sabedoria - o lado épico da verdade - está em extinção". Montenegro não se apropria dos "medos" de Benjamin, não por falta de sensibilidade ou por possuir uma postura "oficialesca" da história. O medo de Benjamin da esterilização da experiência repousava na crença de que a memória, como elemento marginalizado do fazer histórico, pudesse trazer à tona a história dos vencidos e fazer uma história mais verdadeira. Montenegro não se apropria do discurso do marginal como verdade indiscutível, ele se apropria deste 
discurso como mais uma verdade, que constitui uma totalidade fechada em si mesma, mas que dialoga com outras memórias nas mais diversas formas de se compartilhar a experiência.

A filósofa Jeanne Marie Gagnebin também se vale das reflexões de Benjamim para debater memória, esquecimento e narrativa, ao enfatizar a necessidade de "não esquecer dos mortos, dos vencidos, não calar mais uma vez suas vozes" (2006, p. 11). Mas, também destaca outra influência, busca seguir as pegadas de Nietzsche para "não cair na ilusão narcísica de que a atividade intelectual e acadêmica possa encontrar sua justificação definitiva nesse trabalho de acumulação" (GAGNEBIN, 2006, p. 11), pois a vida no presente também exige que se saiba esquecer.

Essa noção, defendida por Gagnebin, de uma memória que saiba equilibrar a ânsia de lembrar com a necessidade de esquecer repousa sobre as leituras de Paul Ricoeur, principalmente em A memória, a história, o esquecimento (2007). Na obra, o filósofo debate a ideia de que a memória pode atuar como remédio e como veneno, fazendo alusão às considerações de Platão em Fedro. A "justa memória" (2007) vem em resposta à exacerbação dos lugares de memória, que se perdem na demasiada comemoração e, portanto, conservação de algumas memórias em especial. A ideia de uma política justa da memória também dialoga com a aspiração do "dever de memória" fruto do Holocausto Nazista, que não abdica a presentificação do trauma, como se a vida não pudesse seguir adiante quando o passado não cessa de ser presente.

Então seria possível fazer uma comparação entre as vítimas dos horrores das Guerras Mundiais e os afetados por desastres no Sul de Santa Catarina? Uma comparação, não. Mas uma relação, sim. No sentido de que ambos podem ser considerados sobreviventes, testemunhas de um acontecimento que alterou as experiências individuais a ponto da narração desta vivência chegar ao limite do indizível.

Ao analisar os escritos de Primo Levi sobre as memórias e experiências no campo de concentração nazista, o historiador Geraldo Antonio Soares (2012) discute a relação entre a memória e o esquecimento em contextos traumáticos. A narrativa do sobrevivente surge como um testemunho que luta contra o esquecimento, sinônimo aqui de inexistência do individuo. O que torna a lembrança necessária é o projeto de futuro, em que as práticas fascistas sejam vistas como abomináveis. A (re)vivência do trauma pela lembrança para narrativa é o preço que o sobrevivente precisa pagar para que as atrocidades do passado não sejam delegadas ao esquecimento. 


\section{Memórias Coletivas, Traumas Individuais}

Em diversos momentos os acontecimentos meta-entrevista transformam as possíveis respostas dos entrevistados ${ }^{6} \mathrm{e}$, também, as próprias memórias dos indivíduos, como foi o caso do professor de Praia Grande, Gustavo dos Santos Reis. As entrevistas estavam sendo feitas na Sala dos Professores do Colégio Estadual Bulcão Viana, Gustavo foi o último a ser entrevistado e ouviu os relatos das outras duas professoras. Ambas haviam mencionado muito rapidamente a enchente de 1974, conferindo mais peso para 1995. Já o professor, o último a falar, vale-se da memória coletiva da região para afirmar a importância da enchente de 1974.

E.: Tu lembra de alguma enchente que tenha acontecido na região?

G. S. dos R.: A mais marcante que todo mundo conhece é a de 1974, eu não vivi, mas é uma enchente histórica, né? Foi muito grande, destruiu grande parte da cidade. É a enchente que mais teve óbitos, né?

E.: Humhum.

G. S. dos R.: Foi nessa época. Eu não era nascido ainda, na casa que eu moro hoje, na casa do meu pai entrou água até meia parede. Mas foi toda a cidade atingida, né? Então é a que eu mais lembro. E agora a de 2007 foi a mais recente assim, que também causou bastantes estragos na minha casa. Estragou o motor do meu carro, eu tava tentando ir para a minha casa. Mas, como eu vi que o rio tinha estourado, não deu para chegar... (REIS, 2012).

Neste caso, a lembrança se mostra em larga medida como uma reconstrução do passado com a ajuda de dados emprestados do presente, "e, além disso, preparada por outras reconstruções feitas em épocas

6 As entrevistas foram realizadas de diversas maneiras. Em poucas ocasiões havia um contato previamente realizado que facilitava a dinâmica da entrevista. Produziu-se um questionário do tipo história de vida, respeitando os caminhos que o entrevistado conferia a própria narrativa. A maioria das entrevistas foi individual, com exceção dos casos familiares em que cônjuges permaneciam juntos, o que acaba criando entrevistas coletivas ou coletivizadas. Algumas pessoas surgiam com indicação, contudo a maioria dos entrevistados foi selecionada pelo fato de residirem em áreas de risco de desastre. 
anteriores e de onde a imagem de outrora se manifestou já bem alterada" (HALBWACHS, 1990, p. 72).

Voltando para a parte norte da região estudada, a experiência de Alcides, o agricultor que escapou de um deslizamento de terra em Treze de Maio-SC, tornou-se parte da memória coletiva do desastre de 1974. O único da família a sobreviver, tomado pela lama e pedaços de árvores, Alcides faz uma promessa a Deus e, segundo ele, com ela ganhou força para, em meio ao caos, buscar por segurança. Depois de ter se arrastado até sua casa, todo machucado e com os pés quebrados, ele é limpo pela sua esposa e cai convalescido. A notícia de sua sobrevivência provavelmente se espalhou no boca a boca e no outro dia um helicóptero aparece para levá-lo ao hospital. Alguns falam em Florianópolis, mas o próprio Alcides atesta que foi para Tubarão. Após dois dias no hospital é trazido para casa, ali fica com sua família dependendo unicamente das ajudas que chegavam. Quando o envio de mantimentos cessou, a família ficou dependente de uma cesta básica trazida todo mês por um amigo de Alcides. Essa situação levou o agricultor, ainda com os pés quebrados a, de joelhos, capinar, arar e plantar uma roça de mandioca para que a família não ficasse tão dependente da solidariedade alheia (MEDEIROS, 2012).

As diversas versões da batalha épica entre Alcides e a queda da "barreira" estão inscritas na memória coletiva local e possuem grande representatividade. As entrevistas que compõem esse trabalho foram realizadas com moradores de áreas de risco que se colocaram à disposição para compartilhar suas lembranças. Desta forma, as narrativas sobre Alcides também são narrativas de todos os sobreviventes, por mais que as pessoas não tenham sentido na pele as experiências do agricultor, a memória individual foi sendo moldada pela coletiva no intuito de comunicar uma série de sofrimentos, que do âmbito pessoal são inenarráveis.

A agricultora Nilza de Medeiros Vieira, também moradora de Treze de Maio, se apropria das experiências do agricultor a ponto de dizer o que Alcides soube quando viu a massa de terra descendo em sua direção.

Esperou ali, mas o outro homem, esse que é o seu Alcides, que a gente falou para vocês irem lá. Ele já saiu correndo e o filho dele mais velho que tinha 18 anos, do outro cara, correu atrás. Ele não ficou com o pai e os irmãozinhos. Aí, ele correu para lá, no caso, eles correram muito e dizem que os matos já vinham grudando eles, não tem? Madeira, árvore, cipó, já veio grudando 
eles. Aí eles conseguiram correr um pouco sem nada, depois um pouco já todo atolado. Todo no pântano. Aí quando passou tudo, aquela madeira, pântano, tudo. Eles ficaram do lado de lá. E ele conseguiu... a roupa deles arrancou tudo. Ele ficou nu, sem nada. Por que os matos iam arrancando tudo, mas ele ia correndo do mesmo jeito. Daí ele pegou e foi lá. E a hora que acabou tudo, que viu a tempestade toda ele sabia que o amigo dele tinha morrido logo atrás dele. Ele tinha certeza. A última vez que ele olhou para o cara, o cara estava com a mão levantada. Aí ele ficou do lado de lá, isso era 9 horas da manhã (VIEIRA, 2012).

A saga de Alcides se tornou emblemática por caracterizar uma excepcionalidade dentro do excepcional: a luta contra as forças da natureza; a religiosidade; a segurança do lar; o sofrimento físico; as privações no pósdesastre; o trabalho árduo na roça; as dificuldades na criação dos filhos. As marcas de um passado de sofrimento do agricultor são compartilhadas na comunidade na medida em que esta história individual serve como referência, tanto para os de fora, quanto os de dentro da comunidade, para explicar uma luta inglória, mas necessária, do agricultor vítima de uma natureza que precisa domar para produzir sua subsistência.

A narrativa de Eliane sobre a passagem do Furacão Catarina é também simbólica, não por uma história de sobrevivência, mas pela "falta" de uma. Inicialmente a professora da Rede Municipal de Sombrio-SC alegou que não tinha vivido o desastre e, desta forma, não teria relato algum para oferecer, pois justamente na hora da passagem do Furacão estava dormindo. Entretanto, concordou em oferecer uma entrevista pelo fato de poder falar sobre a destruição que viu no domingo pela manhã. Eliane explica, que diante da situação de incerteza que se aproximava, pegou sua filha e foram para o apartamento da avó da menina, lá se deitaram juntas na cama e juntas rezaram até dormir.

Eu e minha filha dormimos abraçadinhas e eu não lembro de nada, então eu acho que vem uma forma de gratidão, eu acho que nem vem o medo em si, a gente pode até falar disso depois, mas a primeira imagem vem a imagem de gratidão que Deus é muito bom e eu não vi, né claro, sei de tudo que as pessoas passaram, que eu escutei, mas pra mim em si vem isso...(VEFAGO, 2011). 
A estratégia de Eliane funcionou, apesar do barulho e do medo conseguiu junto com a filha evitar uma experiência que certamente lhe marcaria para a vida toda. Contudo, na continuação do relato, ao passar da descrição do dia de domingo, em que mal podia transitar pela cidade de Sombrio, para a segunda-feira, quando voltaria à escola para lecionar, de sobressalto foi investida pela lembrança das crianças na escola. A perplexidade do corpo docente e o sofrimento dos alunos foram compartilhados por toda a escola.

E. M. V.: Daí quando eu chego na escola. E eu acho que por mais que eu sentia aquilo, não me tocou muito, me tocou mais quando eu cheguei na escola, aí quando eu cheguei na escola, eu vejo que, não tanto em si a estrutura, mas o emocional das pessoas. $\mathrm{Eu}$ acho que isso que mais me tocou, eu lembro até hoje que a diretora foi no palco, ela não conseguia falar né, e tinha alguns alunos indo para escola e muitos chorando né, e eu vi... todas as colegas choraram, uma a casa tinha sido derrubada, a outra não conseguiu dormir, a outra... sabe!? E aí a diretora vai para o palco, assim dizer "Pessoal" - chorando assim "hoje a gente não vai conseguir ter aula, lá na minha casa está acontecendo 'isso', os alunos aqui estão todos abalados, vamos ver o que está acontecendo..." Então aquilo ali sabe? Eu acho que de todo o momento assim, desde o primeiro momento do furacão em si, aquilo ali tocou muito assim, do emocional, daí eu chorei, eu me desesperei também, embora não tivesse acontecido nada comigo aqui, mas eu vi esta coisa... (VEFAGO, 2011).

A narrativa da entrevistada oferece diversos elementos para entender como, mesmo sem ter a experiência, a lembrança do Furacão trouxe um momento traumático vivido pela comunidade. A professora ainda conta que em outro episódio de fortes ventos, logo depois do furacão os alunos ficaram muito nervosos, em virtude da preocupação com os estragos nas casas e a incerteza sobre a condição dos familiares. Como destaca Ricoeur (2007), ao tratar do transplante do conceito utilizado no nível da individualidade para entender uma situação coletivamente compartilhada, é sempre com perdas que a memória ferida é obrigada a se confrontar. No caso do Furacão, para além das perdas materiais, a região perdeu também a segurança, pois depois 
do desastre os moradores passaram a admitir que outros furacões poderiam acontecer. Em se tratando de desastres tidos como naturais as fronteiras do possível foram novamente alargadas.

Como atestou Michael Pollak (1992), são diversas as estratégias produzidas para lidar e para narrar situações traumáticas. Segundo o autor, o silêncio é uma das formas mais comuns de lidar com memórias traumáticas, no entanto esse trabalho de lidar com as lembranças do passado, apesar de também estar inscrito em âmbito coletivo, é, ainda, necessariamente individual. Cabe destacar que as perguntas realizadas nas entrevistas não visavam necessariamente levantar esses momentos delicados na vida dos entrevistados, sempre que o assunto "trauma" ou "sofrimento" surgia, era por via da própria estratégia narrativa dos entrevistados.

Como no caso do agricultor de São João do Sul, do extremo sul catarinense, que também usou o trauma como exemplo para justificar suas ações no pós-desastre.

E.: E como é que foi a reação da sua família durante a enchente?

F. R. da S.: Eu tava do lado de lá, sei lá, a gente não ficou muito...É como diz o ditado, naquelas alturas a gente tinha uma vaca e um porco, e foi enfrentando a enchente para salvar o pouco que tinha.

E.: Sim.

F. R. da S.: Se ficasse parado olhando talvez tivesse ficado traumatizado (SILVA, 2012).

A forma para lidar com o trauma foi o trabalho na própria terra, enquanto a normalidade não fosse restabelecida, a casa recuperada e as terras aradas, a lembrança do sofrimento ainda se faria presente na vida do agricultor. Ainda que a memória da enchente de 1974 esteja plena de sofrimento e provações, o desastre veio mostrar que a moral do trabalho defendida pelo agricultor serviu como um fio condutor que liga as provações do passado a um presente de mais estabilidade.

Entrevistas com caráter estritamente informacional também são ferramentas para entender a seletividade da memória e manobras de alguns entrevistados para manter longe da entrevista os seus sentimentos. O comunicador de Balneário Gaivota, Alfredo Feijão Lopes, trouxe relatos 
precisos sobre a passagem do Furacão, fruto de um trabalho de diversos anos de enquadramento da memória em que oferecia aos seus ouvintes e leitores relatos detalhados da passagem do Catarina. Pollak (1992, p. 203) esclarece que esta forma de negociar experiência e narrativa é comum em personagens públicos que passam a produzir as narrativas com base também na expectativa da audiência.

Diversas situações permeiam a realização das entrevistas de história oral, situações essas que normalmente não compõem o texto final das pesquisas, por não se enquadrarem nas dinâmicas da narrativa composta pelos historiadores ou, até mesmo, pela falta de percepção sobre a aplicabilidade e/ou relevância dos acontecimentos meta-entrevista. Foi o que aconteceu em São João do Sul-SC, pela falta de conhecimento sobre quais pessoas poderiam ser entrevistadas, a Cooperativa de Rizicultores pareceu uma escolha própria para resolver o problema da falta de entrevistados. No local foram feitas duas entrevistas, o segundo entrevistado não se sentiu muito à vontade para oferecer o seu testemunho, foi quando o agricultor que já havia sido entrevistado falou para ele "não ficar de bobagem". Nesse momento, o agricultor que antes parecia contrariado decidiu mostrar naquele contexto que não via mais problemas em dar a entrevista. Entretanto, problema de Nevol Maciel não era dar a entrevista, mas, sim, entrar novamente em contato com uma série de memórias de momentos difíceis.

E.: E quando a gente fala assim "enchente" qual é a primeira que vem na cabeça do senhor?

N. de L. M.: A que me marcou mesmo foi a de 21/03/74.

E.: E por que essa daí marcou mais o senhor?

N. de L. M.: Porque foi muito grande [risos]. Fez muita coisa feia na nossa região.

[silêncio]

E.: E a sua família como ficou?

N. de L. M.: É... Presenciei gente morrendo, tirei gente, achei muitos mortos pelo mato. Tentei tirar alguém não consegui mais, eles morreram. (MACIEL, 2012).

A entrevista foi tão curta quanto as respostas do agricultor. Risos intercalavam as pequenas respostas que caminhavam para um tom de generalização, Nevol buscava não revisitar as memórias que há muito 
estavam esquecidas, ele se amparava na memória coletiva para não carregar sozinho o peso daquelas lembranças.

Diferente das memórias traumáticas analisadas por Pollak (1989) - que no contexto do pós-guerra eram articuladas pelas pessoas para dar sentido a um presente compartilhado por vencedores e vencidos - nas memórias traumáticas produzidas pelos desastres, todos os sobreviventes se veem como vítimas, portanto diferentemente dos contextos estudados pelo sociólogo austríaco, o esquecimento ou mesmo apenas o silêncio, não são vistos como condição necessária para que diferentes grupos sociais dividam o mesmo espaço. Um veredicto entre a complexa relação entre desastres, memória, trauma e esquecimento antes precisa dar conta do caráter de excepcionalidade conferido aos eventos, em nível individual e coletivo, e, igualmente, das formas locais de enquadramento das memórias dos desastres.

\section{Considerações finais}

Enquanto os desastres continuarem a ser compreendidos como “apenas" naturais, uma mitigação real e efetiva permanecerá inalcançável. A lembrança dos desastres que ocorreram no passado pode diminuir o impacto dos desastres no futuro, contudo para o uso da memória coletiva como real estratégia para mitigação é necessário se levar em consideração que existem diversas formas de lembrar e esquecer.

Nas áreas rurais próximas às encostas da Serra Geral onde a frequência das enchentes inibe o total esquecimento dos desastres, as estratégias para sobrevivência gravitam em torno da aceitação do desastre. Nesses locais, entrevistas citaram as poucas estratégias para interagir com o ambiente. Uma delas era a cultura de reconstrução e força de vontade. Nessas situações, o remorso ou o trauma tem que ser constantemente retirados de dentro de casa juntos com tudo mais que a enchente trouxe assim que a água começa a baixar.

Na bacia do Rio Araranguá, que também apresenta alta ocorrência de desastres, a memória coletiva já "terceirizou" o impacto dos eventos, não é mais notadamente Araranguá que sofre com a enchente, mas sim a localidade vulnerável da Barranca. Nesse processo de cristalização da 
segregação espacial, o poder público morosamente espera que a enchente limpe a própria sujeira, varrendo do mapa a comunidade. O que se deixou escondido no passado foi a importância do bairro na formação do município, uma importância deixada de lado porque não condiz com o atual status conferido à localidade.

No extremo sul, a excepcionalidade do Furacão Catarina lhe conferiu diferentes predicados. Se por um lado serviu de "atestado" para explicar que algo até agora incompreensível está acontecendo e transformando a dinâmica dos oceanos com a atmosfera, por outro, a mesma excepcionalidade traz a ideia de que é impossível que o fenômeno se repita. O esquecimento surge como antídoto para a falta de respostas.

No Sul de Santa Catarina, bem como em outras partes do Estado, apesar dos desastres serem um elemento constante na vida das pessoas, ainda são vistos como momentos únicos e excepcionais. Esta percepção se perpetua tanto pela base religiosa, que em última medida inscreve o evento na chave de interpretação do sobrenatural, quanto pela sensação de segurança derivada da vida em sociedade, mais especificamente nas cidades, um ambiente "controlado e mensurado", em que as forças naturais deveriam estar sob controle.

Para lidar com o problema da monumentalização da memória, Paul Ricoeur (2007) cunhou o termo "justa memória". A polissemia presente nessa "justa memória" é basilar para se compreender o posicionamento do autor, sob essa categorização repousa a crença de que o esquecimento pode ser salutar. Ricoeur defende que, em termos individuais e coletivos, a memória feliz é aquela que encontra coerência entre lembrar e esquecer. No intuito de manter vivas as memórias para diminuir o risco de novas intempéries, o estudos sobre a memória dos desastres socioambientais precisam situar-se na difusa fronteira entre a vontade de lembrar e a necessidade de esquecer. 


\section{Entrevistados}

Airton Mendes da Silva (2012), Tubarão.

Alcides Salvador Medeiros (2012), Treze de Maio.

Eliane Vefago (2012), Sombrio.

Gustavo Santos dos Reis (2012), Praia Grande.

Nevol de Lima Maciel (2012), São João do Sul.

\section{Referências bibliográficas}

ALBERTI, V. Histórias dentro da História. In:_ PINSKY, C. B. (Org.). Fontes Históricas. São Paulo: Editora Contexto, 2006.

BANKOFF, G. Cultures of Disaster, Cultures of Coping: Hazard as a Frequent Life Experience in the Philippines. In: MAUCH, C.; PFISTER, C. (Orgs.). Natural disasters, cultural responses: case studies toward a global environmental history. Plymouth: Lexington Books, 2009.

BENJAMIM, W. Magia e técnica. Arte e política: ensaios sobre literatura e história da cultura. São Paulo: Brasiliense, 1985.

GAGNEBIN, J. M. Lembrar escrever esquecer. São Paulo: Ed. 34, 2006.

HALBWACHS, M. A Memória Coletiva. São Paulo: Vértice, 1990. p.25.

LE GOFF, Jacques. História e Memória. Campinas: Ed. da UNICAMP, 2003. p. 9.

MAUCH, C. Introduction. In: MAUCH, C.; PFISTER, C. (Orgs.). Natural disasters, cultural responses: case studies toward a global environmental history. Plymouth: Lexington Books, 2009.

MONTENEGRO, A. T. História, metodologia, memória. São Paulo: Contexto, 2010. 
NIETZSCHE, F. Escritos sobre história. Rio de Janeiro: PUC-RIO. São Paulo: Loyola, 2005

POLLAK, M. Memória e identidade social. Estudos Históricos, vol. 5, $\mathrm{n}^{\mathrm{o}} 10,1992$.

POLLAK, M. Memória, esquecimento, silêncio. Estudos Históricos, vol. 2, $\mathrm{n}^{\circ}$ 3. 1989. RICOEUR, P. A Memória, a história, o esquecimento. Campinas: Ed. Unicamp, 2007.

SCHMIDT, M. L.; MAHFOUD, M. Halbwachs: memória coletiva e experiência. Psicologia USP, São Paulo, v. 4, n. 1-2, 1993. p. 291.

SEDREZ, L. Desastres socioambientais, políticas públicas e memória. In.: NODARI, E. S.; CORREA, S. M. de S. Migrações e Natureza. São Leopoldo: Oikos, 2013.

SEDREZ, L. F. ; MAIA, A. C. N. Narrativas de um Dilúvio Carioca: memória e natureza na Grande Enchente de 1966. História Oral, v. 2, 2011. p. 221-254.

SOARES, Geraldo Antonio. Os tormentos da memória: trauma e narrativa nos escritos de Primo Levi. Varia hist. [online]. 2012, vol.28, n.48, pp. 911-927.

STEINBERG, T. Acts of God - The Unnatural History of Natural Disaster in America. Oxford: Oxford University Press, 2006.

RECEBIDO EM: 17/12/2018

APROVADO EM: 05/04/2019 